\title{
Originals
}

\section{Influence of severe diabetes mellitus early in pregnancy in the rat: effects on insulin sensitivity and insulin secretion in the offspring}

\author{
V. Grill ${ }^{1}$, B. Johansson ${ }^{2}$, P. Jalkanen ${ }^{1}$ and U.J.Eriksson ${ }^{2}$ \\ Department of Endocrinology, Karolinska Hospital, Stockholm and \\ 2 Department of Medical Cell Biology, Uppsala University, Uppsala, Sweden
}

Summary. We studied the influence of severe diabetes early in pregnancy on insulin sensitivity and insulin secretion in the offspring. Diabetes (blood glucose $>20 \mathrm{mmol} / \mathrm{l}$ ) was induced in female Sprague-Dawley rats before mating. Diabetic dams were insulin treated during the second half of pregnancy (mean blood glucose $10.6 \mathrm{mmol} / \mathrm{l}$ ). The offspring were reared by foster mothers. Offspring of both sexes were insulin resistant at four and seven months of age as evidenced by normal glucose tolerance after glucose $(2 \mathrm{~g} / \mathrm{kg}$ body weight intraperitoneally) concomitant with higher than normal rises in insulin levels. Regardless of fetal environment the male rats had higher glucose and insulin levels than the female rats. Insulin responses to glucose $(27 \mathrm{mmol} / \mathrm{l})$ in vitro in perfused pancreases were not increased by maternal diabetes, male gender or higher age. Conversely responses to 3-isobutyl-1-methylxanthine $(1.0 \mathrm{mmol} / \mathrm{l})$ were enhanced by all three conditions. The pancreatic content of insulin was only marginally affected by maternal diabetes. We conclude that severe diabetes during early pregnancy affects glucose homeostasis in the offspring primarily by diminishing insulin sensitivity and that susceptibility to this effect is not sex-or age-dependent.

Key words: Diabetes in pregnancy, insulin secretion, insulin resistance, hyperglycaemia, glucose homeostasis.
Evidence indicates that diabetes in human pregnancy exerts a diabetogenic influence on the offspring $[1,2]$. Data on mechanisms behind such influence have been obtained in animals. Glucose infusions to normal rats during pregnancy result in a diminished insulin release in response to glucose and mild hyperglycaemia in the offspring [3]. These abnormalities were also found in second generation offspring of female rats [4]. In other studies insulin release in response to glucose and arginine was diminished in vitro in offspring of mildly streptozotocin (SZ) diabetic rats, whereas responses to glucose and arginine + glucose were increased in offspring of severely SZ diabetic rats [5]. In the latter group glucose tolerance in vivo was normal, but the ratio of insulin to glucose levels higher than normal, indicating insulin resistance [6]. Insulin resistance was also apparent in another study of the offspring of severely SZ diabetic rats [7]. Taken together animal studies show that maternal diabetes can exert a diabetogenic influence on both insulin sensitivity and insulin secretion in the offspring but that conditions for inducing each of the defects may be different.

Some difficulties exist in the interpretation of the previous studies in rats. The possibility that drugs (streptozo- tocin) given during pregnancy could directly affect the fetus cannot be ruled out, nor a post-delivery influence of nursing from a diabetic mother. It is also difficult to evaluate whether an insulin secretory defect co-exists with insulin resistance or not since insulin resistance has been shown to stimulate Beta-cell secretion [8-10].

Our study aimed to further define the role of maternal diabetes on insulin action and insulin secretion in the offspring. We tested whether diabetes, when present in severe form only during the early part of pregnancy, would induce insulin resistance and/or abnormalities in Beta-cell function in the offspring. To facilitate interpretation of results diabetes was induced by SZ before pregnancy in female rats and the offspring were reared by non-diabetic foster mothers. To evaluate whether Beta-cell function (including time-dynamics of secretion) was appropriate or not in relation to insulin resistance, we compared the impact of the fetal environment factor on insulin secretion with that of sex which also has the potential to influence insulin sensitivity [11, 12]. To determine the constancy of any of the effects we studied the adult rats at two different ages (recognizing also the possibility that age per se may affect insulin sensitivity, [13]). 


\section{Materials and methods}

\section{Animals}

Female Sprague-Dawley rats were obtained from a colony in the Department of Medical Cell Biology in Uppsala. At three months of age (body weights between 250 and $300 \mathrm{~g}$ ) they received a single injection of $40 \mathrm{mg} / \mathrm{kg}$ of streptozotocin (kindly donated by the Upjohn Co., Kalamazoo, Mich., USA) in the tail vein. Animals with blood glucose concentrations exceeding $20 \mathrm{mmol} / \mathrm{l}$ were subsequently mated (one to three weeks following induction of diabetes) with non-diabetic rats. Onset of pregnancy was determined by vaginal smear inspection after over-night mating. The day when a positive smear was found was designated gestational day zero.

Preliminary experiments indicated that insulin treatment during the latter half of pregnancy was necessary to ensure the survival of offspring from the diabetic mothers. Therefore, on gestational day 10, an osmotic minipump (ALZET 2 ML 4, reservoir capacity $2 \mathrm{ml}$, constant pumping rate $2.5 \mu \mathrm{l} / \mathrm{h}, \mathrm{ALZA}$, Palo Alto, Calif., USA) was implanted subcutaneously under ether anaesthesia in the dorsal neck region of each pregnant diabetic rat. The pumps contained Novo Actrapid insulin $(500 \mathrm{IU} / \mathrm{ml}$, diluted to $100 \mathrm{IU} / \mathrm{ml}$, Novo A/S, Bagsvaerd, Denmark) and were connected via an indwelling catheter to the jugular vein of the rat. The diabetic rats thus received $0.25 \mathrm{IU}$ of insulin/h at a constant rate. The blood glucose levels of the rats were monitored daily during insulin treatment by sampling from the tail. If the blood glucose concentration in a pregnant rat exceeded $10 \mathrm{mmol} / \mathrm{l}$, extra insulin (Ultra human, Novo A/S), 5-10 IU, was given s.c. The non-diabetic pregnant rats received no treatment. Pregnancy ended by spontaneous delivery on day 22.

The offspring of the diabetic and the control rats were always reared by non-diabetic foster mothers. Litter sizes were between two and eight pups. At birth litters from control mothers were reduced to the size of litters from diabetic mothers. The animals were weaned at 21 days of age. After weaning they were fed a standard pelleted diet (R3, ALAB, Södertälje, Sweden) and had free access to food and water at all times. A $12 \mathrm{~h}$ light and dark cycle was enforced.

\section{Glucose tolerance tests}

Glucose ( $2 \mathrm{~g} / \mathrm{kg}$ body weight) was administered i.p. to animals at four (all rats) and seven months (some rats) of age. Samples for determination of serum glucose and serum insulin were obtained by tail snipping. The tests were performed around 12.00 hours without prior withdrawal of food.

\section{Perfusion of isolated pancreas}

All animals were anaesthetized by an i. p. injection of pentobarbital (100 mg/kg body weight). Each pancreas was dissected free from adjacent tissues as previously described [14], and perfused via a cannula inserted into the abdominal aorta. The perfusion medium, which was not recirculating, consisted of a Krebs-Henseleit bicarbonate buffer solution [15] supplemented with $20 \mathrm{~g} / \mathrm{l}$ of bovine plasma albumin (Sigma, St. Louis, MO., USA). All experiments included an initial $40 \mathrm{~min}$ equilibration period, of which the last $10 \mathrm{~min}$ are recorded in the Figures ( $\mathrm{min}-10$ to zero), with $3.9 \mathrm{mmol} / \mathrm{l}$ glucose in the perfusate.

The flow rate of perfusion was kept constant at $2.8 \mathrm{ml} / \mathrm{min}$. No visible oedema of the pancreas developed. At intervals indicated in the Figures, samples of the perfusion medium were collected into ice-chilled tubes and stored at $-70^{\circ} \mathrm{C}$ for subsequent RIA of insulin $[16]$.

\section{Extraction of insulin}

At the end of experiments perfused pancreases were rapidly frozen. They were then kept at $-70^{\circ} \mathrm{C}$ until extraction was performed using acid ethanol as previously described [17].

\section{Assays}

Serum insulin was measured by RIA as described [18]. Briefly, $75 \mu 1$ of serum was diluted with $150 \mu \mathrm{l}$ of phosphate buffer before being assayed by RIA. Porcine-antimouse antibodies were used (Novo A/S.) The limit of detection (in undiluted serum) was $0.1 \mathrm{ng} / \mathrm{ml}$. Insulin in perfusate samples was measured in $100 \mu \mathrm{l}$ aliquots as described [16]. Serum glucose was measured by a glucose oxidase method using a Beckman Glucose Analyzer 2 (Beckman Instrument Inc., Fullerton, Calif., USA).

\section{Statistical analysis}

Results are, when not otherwise stated, expressed as mean \pm SEM. Insulin secretion was calculated as the integrated area under the insulin curve for first phase ( $0-5 \mathrm{~min})$ or total response $(0-20 \mathrm{~min})$, the "basal" secretion (=insulin values recorded immediately prior to stimulation) being subtracted. Significance testing was performed using Student's $t$-test (two-tail). A $p$-value of $<0.05$ was considered to be significant.

\section{Results}

\section{Diabetic mothers: blood glucose}

Blood glucose in untreated SZ diabeticrats has been shown to be permanently above $20 \mathrm{mmol} / \mathrm{l}$ [18]. Ketonuria is not present. In our experiments the insulin treatment period was associated with mean moderate hyperglycaemia but a large variation in blood glucose levels. Thus during insulin treatment the median blood glucose was 9.25 and the mean 10.65 with a SD of $6.23 \mathrm{mmol} / \mathrm{l}$.

\section{Offspring: body weight}

Some of the offspring were followed longitudinally (Table 1). The offspring of diabetic mothers weighed less than offspring of control rats at 30 days of age. This dif-

Table 1. Body weight of offspring from streptozotocin (SZ) and control mothers ${ }^{\mathrm{a}}$

\begin{tabular}{|c|c|c|c|c|}
\hline \multirow[t]{3}{*}{ Age } & \multicolumn{4}{|l|}{ Body weight } \\
\hline & \multicolumn{2}{|l|}{ Male rats } & \multicolumn{2}{|l|}{ Female rats } \\
\hline & $\begin{array}{l}\text { Control } \\
\text { mother }\end{array}$ & SZ mother & $\begin{array}{l}\text { Control } \\
\text { mother }\end{array}$ & SZ mother \\
\hline 30 days & $121 \pm 4(8)$ & $107 \pm 2(3)^{b}$ & $105 \pm 3(8)$ & $94 \pm 2(10)^{b}$ \\
\hline 40 days & $202 \pm 5(8)$ & $182 \pm 1(3)$ & $156 \pm 4(8)$ & $144 \pm 2(10)$ \\
\hline 60 days & $354 \pm 8(8)$ & $323 \pm 1(3)$ & $231 \pm 3(8)$ & $224 \pm 3(10)$ \\
\hline 4 months & $487 \pm 13(8)$ & $449 \pm 26(5)$ & $285 \pm 6(5)$ & $299 \pm 19$ \\
\hline 7 months & $568 \pm 12(5)$ & $532 \pm 10(6)$ & $323 \pm 2(4)$ & $329 \pm 2(5)$ \\
\hline
\end{tabular}

a Number of observations in parenthesis; ${ }^{\mathrm{b}} p<0.05$ vs control mothers 
ference reduced with increasing age. Body weights at the time of operation were measured in all rats. Weights were then similar between offspring of control and SZ mothers (Table 1). Body weights were, as expected, lower in female than in male rats.

\section{Glucose tolerance (Fig. 1, Table 2)}

Blood glucose measured before the glucose challenge did not differ with regard to age, sex or fetal environment. The glucose tolerance after glucose injection did not differ with regard to age nor with regard to fetal environment. However, the increment in glucose levels during the test was greater in male than in female offspring both at four and seven months of age and in both offspring of nondiabetic and diabetic rats.

The increase in plasma insulin during the glucose challenge was more marked in males than in females but these
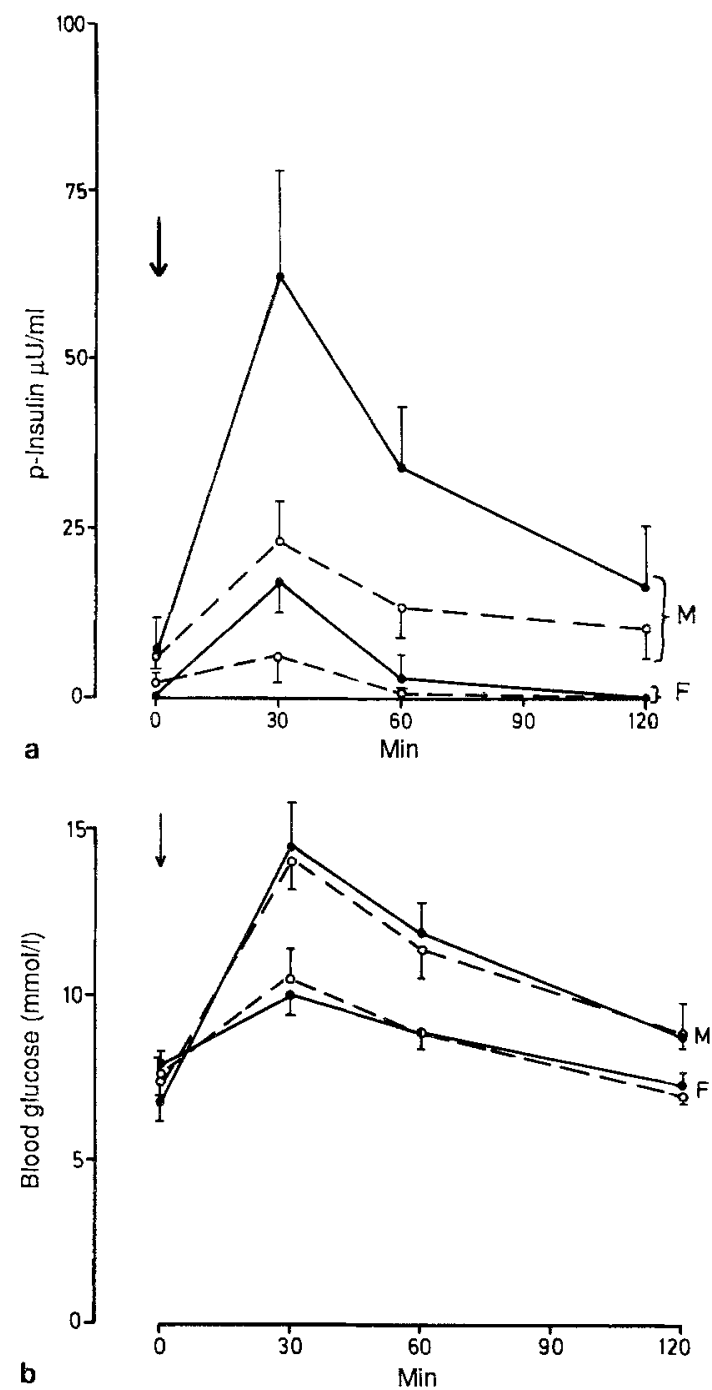

Fig. 1a, b. Insulin (a) and glucose (b) response to an intraperitoneal glucose load at four months of age. $\mathrm{M}=$ male, $\mathrm{F}=$ female rats. $\mathrm{O}-\mathrm{O}=$ offspring from control, $\longrightarrow=$ offspring from streptozotocin-diabetic mothers. Mean \pm SEM of 5-12 experiments. Arrows indicates time of glucose administration
Table 2. Mean increment in glucose and insulin levels during glucose tolerance test

\begin{tabular}{lllc}
\hline Rats & & $\begin{array}{l}\text { Glucose } \\
(\mathrm{mmol} / \mathrm{l})\end{array}$ & Insulin $(\mu \mathrm{U})$ \\
\hline 4 months & Male, control & $3.36 \pm 0.52^{\mathrm{b}}$ & $8.05 \pm 2.07$ \\
4 months & Male, SZ mother & $3.69 \pm 0.78^{\mathrm{b}}$ & $22.77 \pm 6.21^{\mathrm{a}}$ \\
4 months & Female, control & $1.29 \pm 0.57$ & $0.00 \pm 2.07$ \\
4 months & Female, SZ mother & $1.11 \pm 0.34$ & $5.98 \pm 1.38^{\mathrm{a}}$ \\
7 months & Male, control & $3.51 \pm 0.22^{\mathrm{b}}$ & $5.29 \pm 5.98$ \\
7 months & Male, SZ mother & $3.86 \pm 0.32^{\mathrm{b}}$ & $26.62 \pm 3.52^{\mathrm{a}}$ \\
7 months & Female, control & $1.64 \pm 0.58$ & $0.69 \pm 2.07$ \\
7 months & Female, SZ mother & $1.06 \pm 0.30$ & $9.89 \pm 4.14$ \\
\hline
\end{tabular}

significance of difference control vs streptozotocin (SZ) mother, $p<0.05 ;{ }^{b}$ significance of difference males vs females, $p<0.05$

differences corresponded to the differences in glycaemia. The rise in insulin levels after glucose injection was more marked in offspring of SZ diabetic mothers than in offspring of control rats despite similar levels of glycaemia (Table 2). The increment in offspring of SZ diabetic mothers was significant in male rats at four and seven months of age and in female rats at four months of age.

\section{Insulin secretion in vitro (Fig. 2, Table 3)}

"Basal" secretion (in the presence of $3.9 \mathrm{mmol} / 1$ glucose) was similar in all the experimental groups.

Insulin responses to $27 \mathrm{mmol} / \mathrm{l}$ glucose did not differ between groups with regard to time-dynamics nor with regard to total insulin output. There was a tendency for a lower response to glucose at seven months as compared to four months of age in male control rats $(p<0.1)$.

Stimulation with $1.0 \mathrm{mmol} / 1$ 3-isobutyl-1-methylxanthine (IBMX) was performed 20 min after cessation of the exposure to elevated glucose. IBMX was co-perfused with $3.9 \mathrm{mmol} / 1$ glucose. Under these conditions effects of all the three variables tested (age, sex, fetal environment) were observed. IBMX-induced secretion was more marked at four than at seven months of age in control rats of both sexes $(p<0.05)$. In offspring of SZ diabetic rats responses to IBMX seemed more variable than in control rats at four months of age. Only a (non-significant) tendency was seen in offspring of SZ diabetic rats for a higher response at four than at seven months of age. In control rats, the response to IBMX was more marked in male than in female rats at both ages of testing $(p<0.05)$. In offspring of SZ diabetic rats, a higher response in males vs females was evident at seven months of age $(p<0.05)$. Finally, at seven months of age the secretory response was more marked in the offspring of SZ diabetic than of control rats, in both male and female rats $(p<0.05)$.

\section{Pancreatic contents of insulin}

These did not differ between four and seven months of age in any of the groups studied (Table 4). Therefore pancreases from both age groups were pooled for statistical comparisons. In this analysis there was a sex-based difference in the offspring of non-diabetic rats (males having 

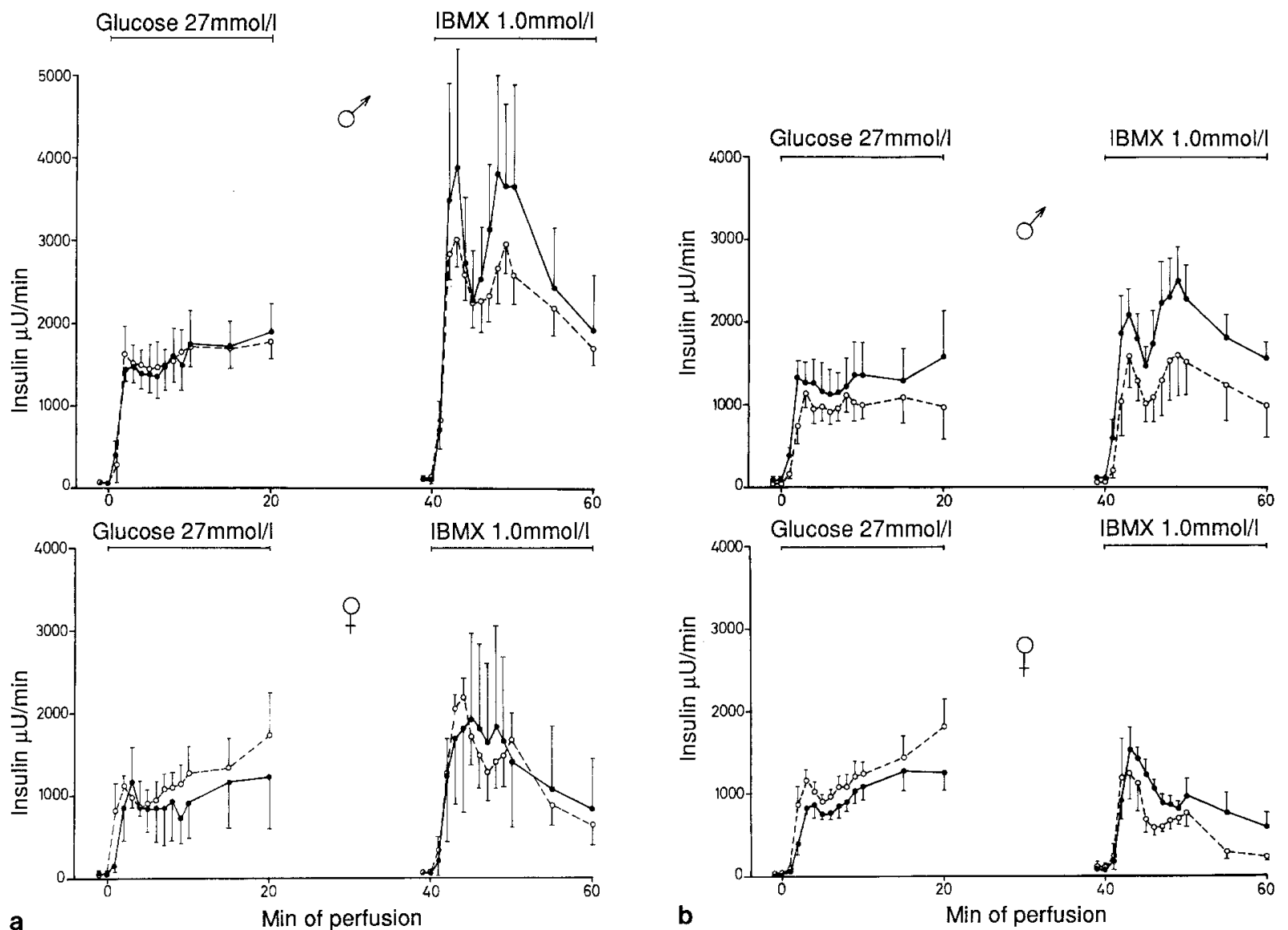

Fig. 2 a, b. Insulin secretion from perfused pancreases of four-month-old (a) and seven-month-old rats $(\mathbf{b}) .0--\mathrm{O}=$ offspring from control, $\longrightarrow=$ offspring from streptozotocin-diabetic mothers. Mean \pm SEM of the number of experiments indicated in Table 3. IBMX $=3$-isobutyl1-methylxanthine

Table 3. Insulin secretion from perfused pancreases ${ }^{\mathrm{a}}$

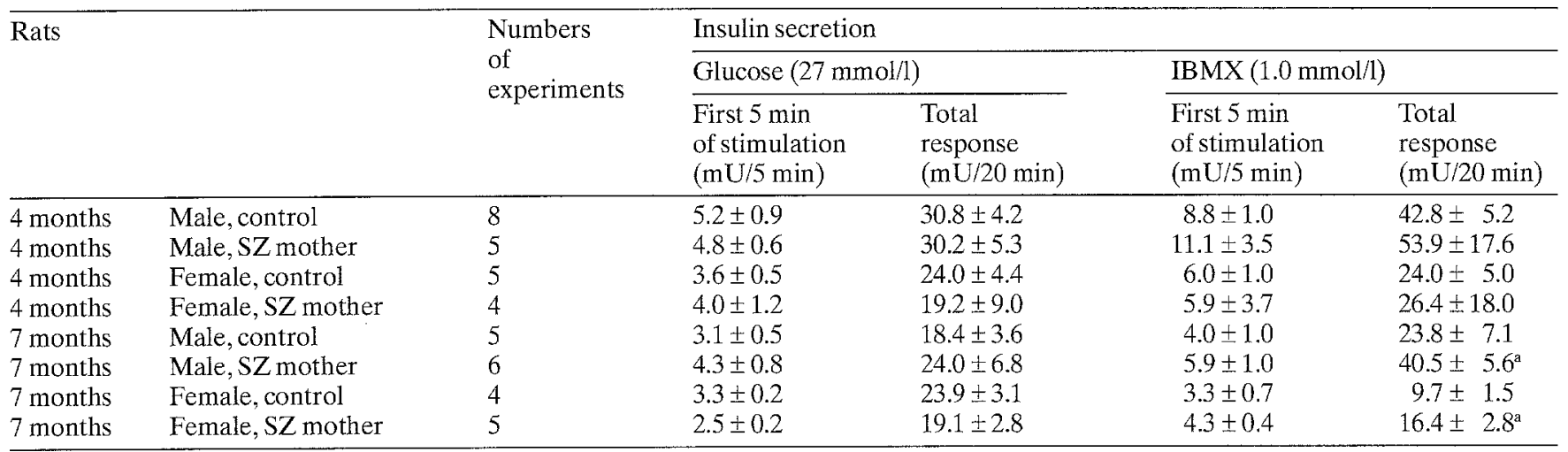

${ }^{a}$ Results of significance testing given in the text.

IBMX = 3-isobutyl-1-methylxanthine.

higher contents than females, $p<0.01)$ but not in the offspring of diabetic mothers $(p>0.2)$. Furthermore, insulin content was slightly greater in male offspring of nondiabetic than in male offspring of diabetic mothers $(p<0.05)$. No such tendency was seen in female offspring ( $p>0.2$ for difference).

Results were also calculated in relation to body weight. When expressed this way there were no differences between groups except that insulin per gramme body weight was lower $(p<0.01)$ in male than in female offspring of diabetic mothers.

\section{Discussion}

Our results clearly demonstrate insulin resistance in the offspring of SZ diabetic rats. These results are in accord with those previously reported by Aerts and co-workers $[5,6]$. Our rats with SZ-diabetic mothers bear a resemblance to the offspring described as severely diabetic by Aerts et al. During the first half of pregnancy our diabetic dams also had severe diabetes with possibly even higher blood glucose values than the rats in the afore-mentioned group. In the previous studies streptozotocin was adminis- 
Table 4. Pancreatic insulin content $(\mathrm{mU})^{\mathrm{a}}$

\begin{tabular}{llll}
\hline Rats & & Insulin (mU) \\
\cline { 3 - 4 } & & Per pancreas & $\begin{array}{l}\text { Per g } \\
\text { body weight }\end{array}$ \\
\hline 4 months & Male, control & $7521 \pm 472(8)$ & $15.55 \pm 1.17$ \\
4 months & Male, SZ mother & $6242 \pm 413(5)$ & $14.09 \pm 1.29$ \\
4 months & Female, control & $4531 \pm 963(5)$ & $16.45 \pm 2.79$ \\
4 months & Female, SZ mother & $5325 \pm 528(4)$ & $17.83 \pm 1.09$ \\
7 months & Male, control & $7215 \pm 492(5)$ & $12.66 \pm 0.65$ \\
7 months & Male, SZ mother & $6371 \pm 677(6)$ & $14.33 \pm 0.60$ \\
7 months & Female, control & $4637 \pm 267(4)$ & $11.97 \pm 1.24$ \\
7 months & Female, SZ mother & $5667 \pm 742(5)$ & $17.27 \pm 2.24$ \\
\hline
\end{tabular}

a Numbers in parenthesis denote numbers of pancreases. Results of significance testing given in text

tered during early pregnancy, leaving open the possibility that the effects on glucose homeostasis in the offspring could, in part at least, be due to side-effects of the drug. Our findings seem to rule out this possibility.

We used foster mothers since nutrition during neonatal age can markedly affect growth rate and glucose homeostasis at adult age $[19,20]$. Our design eliminates poor nursing from a diabetic mother as a factor affecting insulin resistance in offspring of $\mathrm{SZ}$ diabetic rats.

Male rats displayed lower glucose tolerance compared to female rats and had higher insulin responses in vivo. These observations indicate a lower insulin sensitivity in male rats which could be due to the influence of androgens $[11,12]$. The maternal diabetic state thus diminished the insulin sensitivity of the offspring (evidenced by increased ratios of incremental insulin to glucose responses after a glucose challenge) but this effect was more pronounced in the male offspring.

The nature of the insulin resistance effect of maternal diabetes was not studied in detail. Previous studies have shown decreased sensitivity in vivo to insulin in both liver and peripheral tissues [7] in offspring of severely SZ diabetic rats. These effects could be due to insulin resistance per se, or to other hormonal imbalances. Neuroendocrine abnormalities brought about by the intrauterine milieu have been reported in offspring of SZ diabetic rats [21].

Insulin resistance usually leads to a compensatory increase in the in vivo Beta-cell response to different secretagogues [8-10]. Hence the in vitro increased response to IBMX in offspring of diabetic mothers could be regarded as part of normal Beta-cell adaptation and not as a primary abnormality. Rather the question may be raised as to whether insulin responses in vitro were less than appropriate since a hyper-response to IBMX was seen at seven but not at four months of age whereas insulin resistance was present at both ages and no hyper-response to glucose in vitro was seen at any age. Note, however, that the likely difference in insulin sensitivity between sexes that we observe did not correspond to a difference in vitro in glucose-induced insulin secretion between male and female rats born to control mothers. This observation suggests that even in normal Beta cells a decrease in insulin sensitivity does not always lead to an increased insulin response to glucose in vitro.

Insulin responses to IBMX seemed more variable than those elicited by glucose. More importantly they were in- fluenced to a greater extent by in vivo conditions. Hence, with IBMX as secretagogue the secretory response differed not only with regard to maternal diabetes but also with regard to sex (lower response in female rats) and age (lower response at older age). Why IBMX-induced secretion should be more sensitive than glucose-induced secretion in vitro is not clear.

The observation that glucose-induced insulin release was enhanced by maternal diabetes in vivo but not in vitro could be due to the fact that stimulation by glucose in vivo is potentiated by factors not present in vitro such as hormones and amino acids; such secretagogues may be present in higher concentrations or (analogous to IBMX) be more potent in the offspring of SZ diabetic than control rats.

The data on pancreatic insulin content do not indicate generalized diminution of Beta-cell capacity as a result of maternal diabetes. Thus, although pancreatic insulin content was significantly greater in male offspring of control than of diabetic mothers, the difference was small and may be secondary to increased demands for release due to insulin resistance. Furthermore, no such difference was found in female rats.

Taken together, our data fail to document (although they do not rule out) abnormal regulation of Beta-cell secretion in our offspring of SZ diabetic rats. The failure to show decreased Beta-cell function in the offspring of our diabetic rats appears discrepant with data obtained in glucose-infused rats $[3,4]$. In these experiments mild hyperglycaemia during the last week of pregnancy was able to induce a lasting decrease in Beta-cell function in the offspring. In our experiments mean blood glucose was moderately elevated during the same period of gestation, yet Beta-cell function was not clearly abnormal in the offspring. It may be that the differences in glycaemia that existed between the studies could be important. Another reason for the discrepancy could be species differences (Wistar rats were used in previous, Sprague-Dawley rats in the present experiments). In this context it should be stressed that even small genomic differences between strains can markedly influence susceptibility to other effects of maternal diabetes. Hence maternal diabetes induces malformations in some substrains of SpragueDawley rats but not in others. (Our substrain was malformation - prone).

In summary severe diabetes during early pregnancy affects glucose homeostasis in the offspring predominantly by diminishing insulin sensitivity. Susceptibility to this effect is not sex-or age-dependent.

Acknowledgements. The authors are grateful to Ms. P. Wentzel, Ms. M.Papazians and Ms. M.Halin for expert technical assistance. This investigation was supported by the Swedish Medical Research Council (Grants no 19X-04540 and 12X-7475) the "Expressen" Prenatal Research Foundation, The Swedish Diabetes Association, The Nordic Insulin Fund and The Swedish Hoechst Diabetes Fund.

\section{References}

1. Pettitt DJ, Kirk A, Aleck H, Baird R, Carraher MJ, Bennett PH, Knowler WC (1988) Congenital susceptibility to NIDDM. Role of intrauterine environment. Diabetes 37: 622-628 
2. Martin AO, Simpson JO, Ober C, Freinkel N (1985) Frequency of diabetes mellitus in probands with gestational diabetes: possible maternal influence on the predisposition to maternal diabetes. Am J Obstet Gynecol 151: 471-473

3. Bihoreau MT, Ktorza A, Kinebayan MF, Picon L (1986) Impaired glucose homeostasis in adult rats from hyperglycemic mothers. Diabetes 35:979-984

4. Gauguier D, Bihoreau M-T, Ktorza A, Berthault M-F, Picon L (1990) Inheritance of diabetes mellitus as a consequence of gestational hyperglycemia in rats. Diabetes 39: 734-740

5. Aerts L, Sodoyez-Goffaux F, Sodoyez JC, Malaisse WJ, van Assche FA (1988) The diabetic intrauterine milieu has a long-lasting effect on insulin secretion by B-cells and on insulin uptake by target tissues. Am J Obstet Gynecol 159: 1287-1292

6. Aerts L, van Assche FA (1979) Is gestational diabetes an acquired condition? J Develop Physiol 1: 219-225

7. Holemans K, Aerts L, van Assche FA (1989) Decreased insulin sensitivity and responsiveness in the adult offspring of streptozotocin - diabetic mothers. Diabetologia 32: 497 (Abstract)

8. Karam JH, Grodsky GM, Forsham PH (1963) Excessive insulin response to glucose in obese subjects as measured by immunochemical assay. Diabetes 12: 196-204

9. Beard JC, Halter JB, Best JD, Pfeifer MA, Porte D (1984) Dexamethasone-induced insulin resistance enhances $B$ cell responsiveness to glucose level in normal men. Am J Physiol 247: E592-E596

10. Kahn S, Beard J, Schwartz M, Ward K, Ding H, Bergman R, Taborsky G, Porte D (1989) Increased $\beta$-cell secretory capacity as mechanism for islet adaptation to nicotinic acid-induced insulin resistance. Diabetes 38: 562-568

11. Bonner-Weir S, Trent DF, Honey RN, Weir GC (1981) Responses of neonatal rat islets to streptozotocin. Limited B-cell regeneration and hyperglycemia. Diabetes 30:64-69

12. Östenson CG, Grill V, Roos M (1989) Studies on sex dependency of B-cell susceptibility to streptozotocin in a rat model of type 2 diabetes mellitus. Exp Clin Endocrinol 93: 241-247

13. Davidson MB (1979) The effect of aging on carbohydrate metabolism: a review of the English literature and a practical approach to the diagnosis of diabetes mellitus in the elderly. Metabolism 28: 688-705
14. Loubatières AL, Mariani MM, Ribes G, de Malbosc H, Chapal J (1969) Étude expérimentale d'un nouveau sulfamide hypoglycémiant particulièrement actif le HB419 ou glibenclamide. Diabetologia 5 : $1-10$

15. Umbreit WW, Burris RH, Stauffer JF (1957) Manometric Techniques. Burgess, Minneapolis, pp 149-150

16. Herbert V, Lau KS, Gottlieb CW, Bleicher SJ (1965) Coated charcoal immunoassay of insulin. J Clin Endocrinol Metab 25: $1375-1384$

17. Grill V, Efendic S (1983) Loss of priming effect of glucose on Aand $D$-cell secretion in perfused pancreas from alloxan-diabetic rats: role of insulin and alloxan. Diabetologia 24: 47-51

18. Eriksson U, Andersson A, Efendic S, Elde R, Hellerström C (1980) Diabetes in pregnancy: effects on the foetal and newborn rat with particular regard to body weight, serum insulin concentration and pancreatic contents of insulin, glucagon and somatostatin. Acta Endocrinol 94: 354-364

19. Asplund K (1972) Effects of postnatal feeding on the functional maturation of pancreatic islet B-cells of neonatal rats. Diabetologia 8: 153-159

20. Swenne I, Crace CJ, Milner RDG (1987) Persistent impairment of insulin secretory response to glucose in adult rats after limited period of protein-calorie malnutrition early in life. Diabetes 36 : 454-458

21. Foglia VG, Heller CL, Becú-Villalobos D, Weisenberg LS, Lacau de Mengido IM, Piroli G, Libertein C, DeNicola AF (1987) Neuroendocrine changes in female rats born from streptozotocin-diabetic mothers. Horm Metab Res 19: 545-548

22. Eriksson RSM, Thunberg L, Eriksson UJ (1989) Effects of interrupted insulin treatment on fetal outcome of pregnant diabetic rats. Diabetes 38: 764-772

Received: 30 August 1990

and in revised form: 7 January 1991

Dr. V. Grill

Department of Endocrinology

Karolinska Hospital

S-10401 Stockholm

Sweden 